\title{
Case Report \\ Genotype-Phenotype Characterization of Wolf-Hirschhorn Syndrome Confirmed by FISH: Case Reports
}

\author{
F. Sheth, ${ }^{1}$ O. R. Akinde, ${ }^{1}$ C. Datar, ${ }^{2}$ O. V. Adeteye, ${ }^{1}$ and J. Sheth ${ }^{1}$ \\ ${ }^{1}$ FRIGE's Institute of Human Genetics, FRIGE House, Satellite, Ahmedabad 380015, India \\ ${ }^{2}$ Sahyadri Medical Genetics and Tissue Engineering Facility, 1170/01, Barve Memorial Complex, J.M. Road, Pune 411005, India
}

Correspondence should be addressed to F. Sheth, fshethad1@googlemail.com

Received 20 September 2012; Accepted 24 October 2012

Academic Editors: C. López Ginés and H. A. Stirnadel

Copyright $(2012$ F. Sheth et al. This is an open access article distributed under the Creative Commons Attribution License, which permits unrestricted use, distribution, and reproduction in any medium, provided the original work is properly cited.

\begin{abstract}
The Wolf-Hirschhorn syndrome (WHS) is a multiple malformation and contiguous gene syndrome resulting from the deletion encompassing a 4 p16.3 region. A microscopically visible terminal deletion on chromosome $4 \mathrm{p}(4 \mathrm{p} 16 \rightarrow$ pter) was detected in Case 1 with full blown features of WHS. The second case which had an interstitial microdeletion encompassing WHSC 1 and WHSC 2 genes at 4p16.3 presented with less striking clinical features of WHS and had an apparently "normal" karyotype. The severity of the clinical presentation was as a result of haploinsufficiency and interaction with surrounding genes as well as mutations in modifier genes located outside the WHSCR regions. The study emphasized that an individual with a strong clinical suspicion of chromosomal abnormality and a normal conventional cytogenetic study should be further investigated using molecular cytogenetic techniques such as fluorescence in situ hybridization (FISH) or array-comparative genomic hybridization (a-CGH).
\end{abstract}

\section{Introduction}

The Wolf-Hirschhorn syndrome (WHS) is a well-known, multiple malformation syndrome, which affects 1 in 50,000 live births with a 2:1 female-to-male ratio $[1,2]$. WHS is caused by a partial loss of genetic material from the distal portion of the $\mathrm{p}$ arm of chromosome 4 and is considered as a contiguous gene syndrome [3]. About 50$60 \%$ of the individuals with WHS have a microscopically visible de novo deletion encompassing a 4 p16.3 region. The remaining $40 \%-45 \%$ have an unbalanced translocation, where as nearly as $55 \%$ can be detected by conventional banding techniques alone. These deletions may be de novo or inherited from a parent with a balanced rearrangement $[4,5]$. In more than $95 \%$ of the cases, these deletions are diagnosed by fluorescent in situ hybridization (FISH) using Wolf-Hirschhorn syndrome critical region (WHSCR) specific probes.

WHS has attracted considerable attention and is associated with a variety of clinical features ranging from mild to severe mental retardation, hypotonia, growth delay, seizures, and specific craniofacial manifestations [2]. Some of these individuals do not display features consistent with WHS, whereas others have a clinical presentation with some overlap to the WHS phenotype.

Deletion in the WHSCR regions have been considered as the hallmark of WHS. Mapping efforts have identified two different sized overlapping deletions defining the WolfHirschhorn syndrome critical region 1 and 2 (WHSCR 1 and 2) $[2,6,7]$. These regions are suggested as being responsible for at least two of the core clinical manifestations of WHSthe developmental delay and the facial gestalt [8].

In this paper, we present 2 cases: deletion of a genomic segment on chromosome 4 (p16 $\rightarrow$ pter) in Case 1 with a loss of multiple overlapping genes and in another case a deletion encompassing WHSCR 1 and 2. These patients are clinically suspected with severe and mild WHS features, respectively.

Case 1. An eight-month-old girl presented with dysmorphic features, developmental delay, and mental retardation. She was the fifth child born to nonconsanguineous parents. The mother had an uneventful pregnancy. The father was 36 years old and the mother was 32 years old at the time of the delivery. The baby was born with low birth weight of $1.8 \mathrm{~kg}$. 


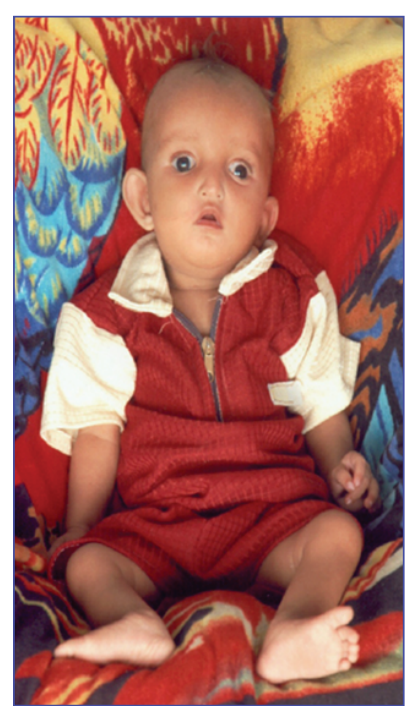

FIgURE 1: Depicting phenotypes of Case 1.

At the age of 8 months she was admitted to the hospital due to the failure to thrive and was later found to have left side massive pneumothorax and cyanotic changes secondary to ASD with left-to-right shunt.

The clinical examination revealed marked growth retardation, microcephaly, prominent glabella, short philtrum, micrognathia, high forehead, preauricular tags with low set ears, narrow external auditory canals, strabismus, hypertelorism, iris coloboma, wide nasal bridge, downturned corners of the mouth with a fish-type appearance, and hyper convex fingernails (Figure 1).

Case 2. A four-year-old boy, the first child born to young and healthy nonconsanguineous parents with birth weight of $2.7 \mathrm{~kg}$, was born at term by vaginal delivery. The age of the father was 33 years and the mother was 22 years at the time of the child's birth. The child presented with ophthalmic abnormalities, dysmorphic features and, delayed eye opening at neonatal period and was referred for clinical assessment.

The clinical examination of this patient revealed relative macrocephaly, prominent glabellas, narrow palpebral fissures, microophthalmia, microcornea, coloboma of iris, hypertelorism, low set ears, broad nasal root with high arched palate, hypodontia and dental caries (Figure 2). Nystagmus was noted on the clinical examination and the visual acuity was reduced to 1 meter. The B-scan showed uveal coloboma, posterior vitreous detachment, retinal detachment, macular scar in the left eye, and ahpakia in the right eye in addition to the above findings. Supplementary investigations showed very mildly affected cognition, normal growth, and development of the CNS with no neurological deficits. Systemic examinations were observed to be normal.

Cytogenetic study was carried out using peripheral blood lymphocytes by GTG banding according to the standard procedures at 550 band resolution and 25 metaphases were analyzed and karyotyped as per ISCN guidelines [9]. Metaphase analysis of Case 1 revealed a female karyotype, of

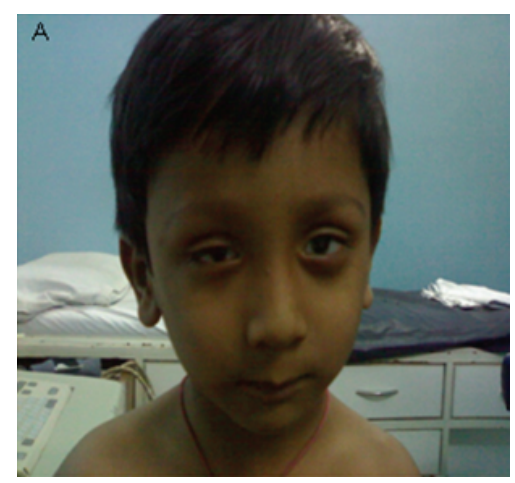

(a)

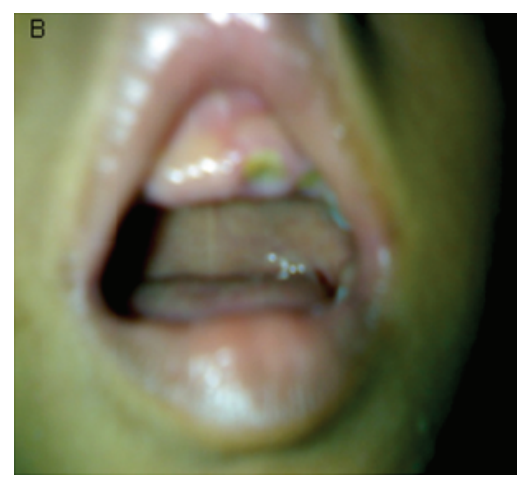

(b)

FIGURE 2: Facial feature of Case 2, (a) showing facial dysmorphism and (b) high arched palate and dental carries.

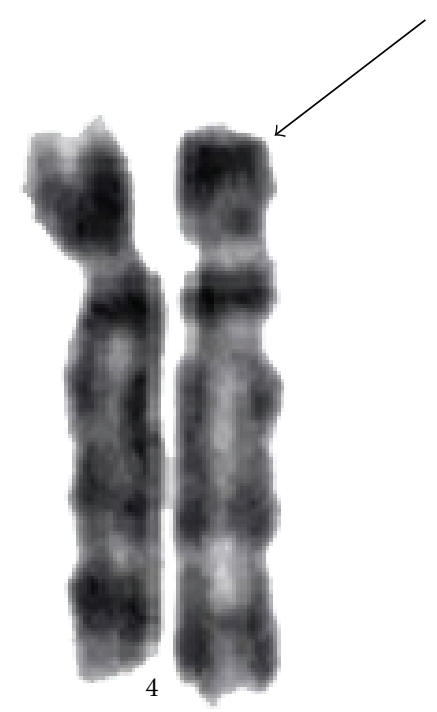

Figure 3: Arrow showing deletion at chromosome 4p16.

$46, \mathrm{XX}, \operatorname{der}(4) \operatorname{del}(4)(\mathrm{p} 16 \rightarrow$ pter $)$ and that of Case 2 revealed a normal male karyotype, that is, 46,XY. Parents were chromosomally normal confirming de novo origin in both cases (Figure 3).

A submicroscopic deletion study was performed using the fluorescence in situ hybridization (FISH) analysis on 
TABLE 1: Comparison of phenotypes in the cases and frequency of each phenotype in literatures.

\begin{tabular}{|c|c|c|c|c|}
\hline Clinical Features & $\begin{array}{l}\text { Wolf-Hirschhorn } \\
\text { phenotypes } 4 \text { p } 16.3\end{array}$ & $\begin{array}{c}\text { Case } 1 \\
4 \mathrm{p} 16-\mathrm{pter} \\
(8.5 \mathrm{Mb})\end{array}$ & $\begin{array}{c}\text { Case } 2 \\
4 \mathrm{p} 16.3 \\
(3.5 \mathrm{Mb})\end{array}$ & $\begin{array}{l}\text { Frequency of phenotypes } \\
4 \mathrm{p} 15.32-4 \mathrm{p} 16.3[3,12] .\end{array}$ \\
\hline Dysplastic ears & + & + & + & $80 \%$ \\
\hline Hypotonia & + & + & + & $75 \%$ \\
\hline High forehead & + & + & + & $50 \%$ \\
\hline Colobomata of iris & + & + & + & $40 \%$ \\
\hline Broad or beak nose & + & + & + & $?$ \\
\hline Hypertelorism & + & + & + & $?$ \\
\hline Prominent glabella & + & + & + & $?$ \\
\hline Microcephaly & + & + & - & $90 \%$ \\
\hline Mental retardation & + & + & - & $75 \%$ \\
\hline Growth retardation & + & + & - & $75 \%$ \\
\hline Congenital defects (ASD) & + & + & - & $50 \%$ \\
\hline Micrognathia & + & + & - & $?$ \\
\hline Short philtrum & + & + & - & $?$ \\
\hline Preauricular tags & + & + & - & $?$ \\
\hline $\begin{array}{l}\text { Downturned corners of the mouth } \\
\text { with fish-type appearance }\end{array}$ & + & + & - & $?$ \\
\hline High arched palate & + & - & + & $30 \%$ \\
\hline Nystagmus & - & + & + & $?$ \\
\hline Hyper convex finger nails & - & + & - & $60 \%$ \\
\hline Dental caries & - & - & + & $50 \%$ \\
\hline Narrow palpebral fissures & - & - & + & $50 \%$ \\
\hline Microcornea & - & - & + & $40 \%$ \\
\hline Strabismus & - & + & - & $?$ \\
\hline Micro-ophthalmia & - & - & + & $?$ \\
\hline Seizuires & + & - & - & $93 \%$ \\
\hline Feeding difficulty & + & - & - & $75 \%$ \\
\hline Skeletal anomalies & + & - & - & $60 \%$ \\
\hline Renal anomalies & + & - & - & $40 \%$ \\
\hline Hypospadias & + & - & - & $40 \%$ \\
\hline Epicanthus & + & - & - & $?$ \\
\hline
\end{tabular}

the cytogenetic preparations using Kreatech dual colour probes. WHSC1 probe encompassing WHSC1 gene was labeled with spectrum orange and control probe SE 4 was labeled with spectrum green as per manufacturer's recommendation. Locus specific BAC probe (RP11-262P20) covering WHSC 1 and WHSC 2 genes was labeled with spectrum orange and a control BAC probe (RP11-195L6), positioned at 4q26, was labeled with spectrum green. Various overlapping $\mathrm{BAC}$ clones were used to narrow down the break site on chromosome 4 and were labeled as per the Vysis protocol as described by Menten et al. [10]. The signals were visualized by digital imaging microscopy and pseudocolouring was carried out using Adobe photoshop.

\section{Discussion}

Characteristic facial appearance and intellectual disability are the two major phenotypic features that constitute one of the major diagnostic markers for WHS. WHS is most often caused by terminal deletions involving chromosome 4 p16.3 and may extend as far as 4 p14 [11]. Interstitial deletions are less frequently reported $[6,7,12]$, but are of a particular interest since they facilitate genotype-phenotype correlations and thus may aid in the search for causative genes.

The variability of WHS presentation has been attributed to the size of deletions. Zollino et al. [2] defines a patient with deletion between 5-18 Mb as "Classic WHS", which presents with severe psychomotor delay and commonly has major malformations. Case 1 having $8.2 \mathrm{Mb}$ deletion is consistent with several features reported in the literature as diagnostic markers for major WHS, which include microcephaly, mental retardation, growth retardation, high forehead, downturned mouth, hypotonia, congenital heart defects, coloboma, and dysplastic ears. Moreover, other features such as beaked nose, short philtrum, hypertelorism, nystagmus, 
coloboma, and prominent glabella are reported to be of low frequency as shown in Table 1 . The variation in the size of the deleted segment and the effect of gene interaction might explain the absence of other reported phenotypes of WHS in this patient [13]. The phenotypic severity in this case is consistent with the length of deletion involving the WHSCR 1 , WHSCR 2, and beyond (4p16 $\rightarrow$ pter). The deleted segment includes all the genes involved in the development of the core features of WHS and other multiple genes that act as master regulators of different developmental pathways. Typically, the MSX1 gene located at 4p16.2, outside the WHSCR 1 and 2 , is deleted when the microscopically visible deletion involving 4p is involved. Haploinsufficiency of MSX1 gene probably disrupts the regulation of several associated genes particularly involved in the development of the mouth, teeth, and the facial dysmorphisms [14, 15]. Hence, facial dysmorphism observed in Case 1 could be partly attributed to the loss of MSX1 gene. This further supports the fact that the interaction with surrounding genes and mutations in modifier genes located outside the WHSCR regions account for the increase in phenotypic expression found in WHS with larger deletion. The plausible candidate gene for a part of craniofacial phenotype of WHS has been traced to FGFR1 [16]. Case 2 has a deletion of $\sim 193 \mathrm{~kb}$ and presents with less striking features of WHS, such as mild retardation and fluent language without major malformation as compared to Case 1. This is consistent with Zollino's classification of "mild WHS" with a deletion of less than $3.5 \mathrm{Mb}$, with limited expression or absence of major malformations [2] as observed in Table 1. Milder phenotypic presentation has also been shown by South et al. in 2007 where the deletion region is small $(1.78 \mathrm{Mb})$. The break point near or within the region of WHSCR gene and harbors LETM1 may play a direct role in the seizure development if it gets deleted which has not been detected in our case [7]. Both WHSCR 1 and 2 were deleted in both cases. Case 1 has deletions that encompass beyond the critical regions to the telomeric end, while Case 2 has interstitial deletion involving only the WHSCR 1 and 2 and, hence, the variation in presentation. However, because of the deletion of WHSCR 1 and 2 in both cases, demonstration of some of the features of WHS, which includes high forehead, broad beaked nose, hypotonia, dysplastic ears, hypertelorism, coloboma, prominent glabella and nystagmus, are found in both cases, while dental caries, narrow palpebral fissure, microophthalmia and microcornea were only demonstrated in Case 2 . The facial dysmorphism seen in Cases 1 and 2 could be due to the loss of several gene functions owing to both deletion and dysregulation.

Hannes et al. [17] demonstrated 3D facial capturing on patients suggestive for WHS with deletions either located distally to the WHSCR 1 and/or overlapping the WHSCR 1 using dense surface modeling and pattern recognition technique. Full complement of the WHS facial characteristics was noted in typical WHS patients as seen in the two cases of this study. Interestingly, none of these patients were reported to have cleft palate as compared to Hannes et al. [17] findings. Hammond et al. [16] identified a $432 \mathrm{~kb}$ deletion located $600 \mathrm{~kb}$ proximal to both WHSCR 1 and 2 in a patient with a WHS phenotype and found that there are seven genes underlying this deleted region. It was hypothesized that the loci within WHSCR 1 and 2 exert long range effects on the deleted region. Thus in an event of WHSCR deletion, there will be dysregulation of the genes in a defined window or loci additive to the WHS critical regions leading to the increased phenotypic expression. The interplay of multiple genes in the deleted region and surroundings genes is essential for the expression of complete distinct facial phenotype seen in WHS patients. However, the reasons for the presence of certain phenotypes in Case 2 which are absent in Case 1 remain to be explained.

Conclusively, this study has shown that WHS encompasses a spectrum of phenotypes. Most likely to be missed is a microdeletion that presents milder or less striking clinical features and has apparently a "normal" karyotype. These will need molecular cytogenetic techniques (FISH/array comparative genomic hybridization), for further confirmation and following this, the inheritance pattern needs to be confirmed by studying parents and prenatal diagnosis can be offered accordingly.

\section{Acknowledgments}

All the probes were kindly provided by Dr. Andrieux J. (France). The work is partly supported by the Department of Biotechnology (DBT), India.

\section{References}

[1] N. L. Shannon, E. L. Maltby, A. S. Rigby, and O. W. J. Quarrell, "An epidemiological study of Wolf-Hirschhorn syndrome: life expectancy and cause of mortality," Journal of Medical Genetics, vol. 38, no. 10, pp. 674-679, 2001.

[2] M. Zollino, R. Lecce, R. Fischetto et al., "Mapping the Wolf-Hirschhorn syndrome phenotype outside the currently accepted WHS critical region and defining a new critical region, WHSCR-2," American Journal of Human Genetics, vol. 72, no. 3, pp. 590-597, 2003.

[3] A. Battaglia, T. Filippi, and J. C. Carey, "Update on the clinical features and natural history of Wolf-Hirschhorn (4p-) syndrome: experience with 87 patients and recommendations for routine health supervision," American Journal of Medical Genetics, Part C, vol. 148, no. 4, pp. 246-251, 2008.

[4] A. Battaglia, J. C. Carey, S. T. South, and T. J. Wright, "Wolfhirschhorn syndrome," in Gene Reviews, R. A. Pagon, T. D. Bird, C. R. Dolar, and K. Stephens, Eds., University of Washington, Seattle, Wash, USA, 2010.

[5] D. Wieczorek, M. Krause, F. Majewski et al., "Unexpected high frequency of de novo unbalanced translocations in patients with wolf-hirrschhorn syndrome (WHS)," Journal of Medical Genetics, vol. 37, no. 10, pp. 798-804, 2000.

[6] G. Van Buggenhout, C. Melotte, B. Dutta et al., "Mild WolfHirschhorn syndrome: micro-array CGH analysis of atypical 4p16.3 deletions enables refinement of the genotypephenotype map," Journal of Medical Genetics, vol. 41, no. 9, pp. 691-698, 2004.

[7] S. T. South, S. B. Bleyl, and J. C. Carey, "Two unique patients with novel microdeletion in 4 p16.3 that exclude the WHS critical regions. Implication for critical region designation," American Journal of Medical Genetics, Part A, vol. 143, no. 18, pp. 2137-2142, 2007. 
[8] K. Izumi, H. Okuno, K. Maeyama et al., "Interstitial microdeletion of $4 \mathrm{p} 16.3$ : contribution of WHSC1 haploinsufficiency to the pathogenesis of developmental delay in wolfhirschhorn syndrome," American Journal of Medical Genetics, Part A, vol. 152A, no. 4, pp. 1028-1032, 2010.

[9] L. G. Shaffer, M. L. Slovak, and J. C. Lynda, An International System for Human Cytogenetic Nomenculature, Karger Press, 2009.

[10] B. Menten, N. Maas, B. Thienpont et al., "Emerging patterns of cryptic chromosomal imbalance in patients with idiopathic mental retardation and multiple congenital anomalies: a new series of 140 patients and review of published reports," Journal of Medical Genetics, vol. 43, no. 8, pp. 625-633, 2006.

[11] A. Basinko, N. Douet-Guilbert, P. Parent et al., "Familial interstitial deletion of the short arm of chromosome 4 (p15.33-p16.3) characterized by molecular cytogenetic analysis," American Journal of Medical Genetics, Part A, vol. 146, no. 7, pp. 899-903, 2008.

[12] A. Rauch, S. Schellmoser, C. Kraus et al., "First known microdeletion within the wolf-hirschhorn-syndrome critical region refines genotype-phenotype correlation," American Journal of Medical Genetics, vol. 99, no. 4, pp. 338-342, 2001.

[13] D. Wieczorek, M. Krause, F. Majewski et al., "Effect of the size of the deletion and clinical manifestation in wolf-hirschhorn syndrome: analysis of 13 patients with a de novo deletion," European Journal of Human Genetics, vol. 8, no. 7, pp. 519526, 2000.

[14] E. R. Silva, C. R. Reis-Filho, M. H. Napimoga, and J. B. Alves, "Polymorphism in the Msxl gene associated with hypodontia in a Brazilian family," Journal of Oral Science, vol. 51, no. 3, pp. 341-345, 2009.

[15] N. J. Johnston and D. L. Franklin, "Dental findings of a child with Wolf-Hirschhorn syndrome," International Journal of Paediatric Dentistry, vol. 16, no. 2, pp. 139-142, 2006.

[16] P. Hammond, F. Hannes, M. Suttie, K. Devriend, J. R. Vernmeess, F. Faravelli et al., "Fine-grained facial phenotypegenotype analysis in Wolf-Hirshhorn syndrome," European Journal of Human Genetics, vol. 20, no. 1, pp. 33-40, 2012.

[17] F. Hannes, P. Hammond, O. Quarrel et al., "proximal of the critical deletion region is associated with wolf-hirschhorn syndrome," American Journal of Medical Genetics Part A, vol. 158, no. 5, pp. 996-1004, 2012. 


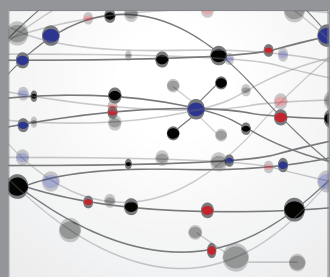

The Scientific World Journal
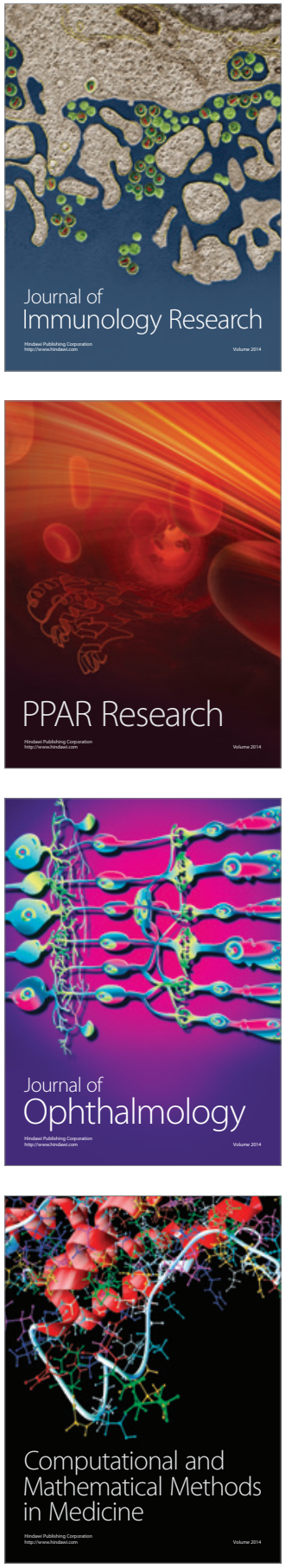

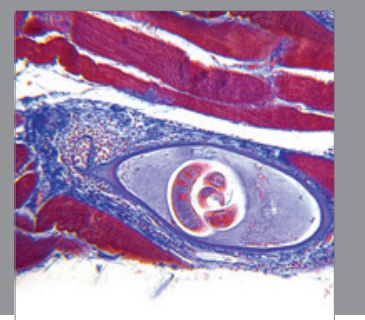

Gastroenterology

Research and Practice
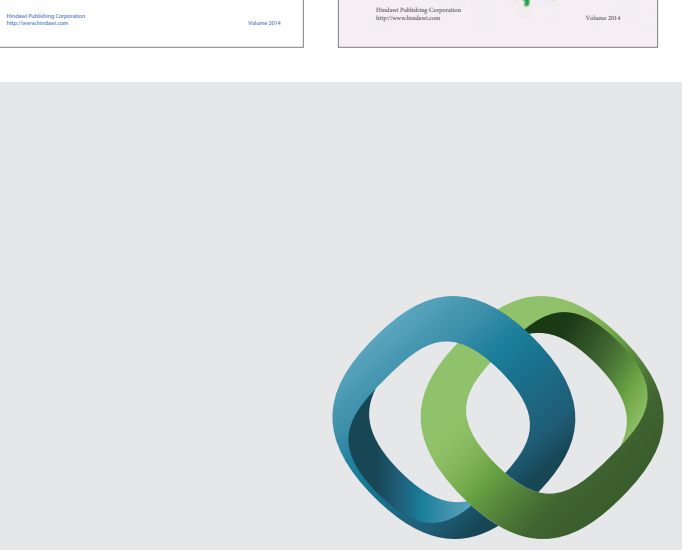

\section{Hindawi}

Submit your manuscripts at

http://www.hindawi.com
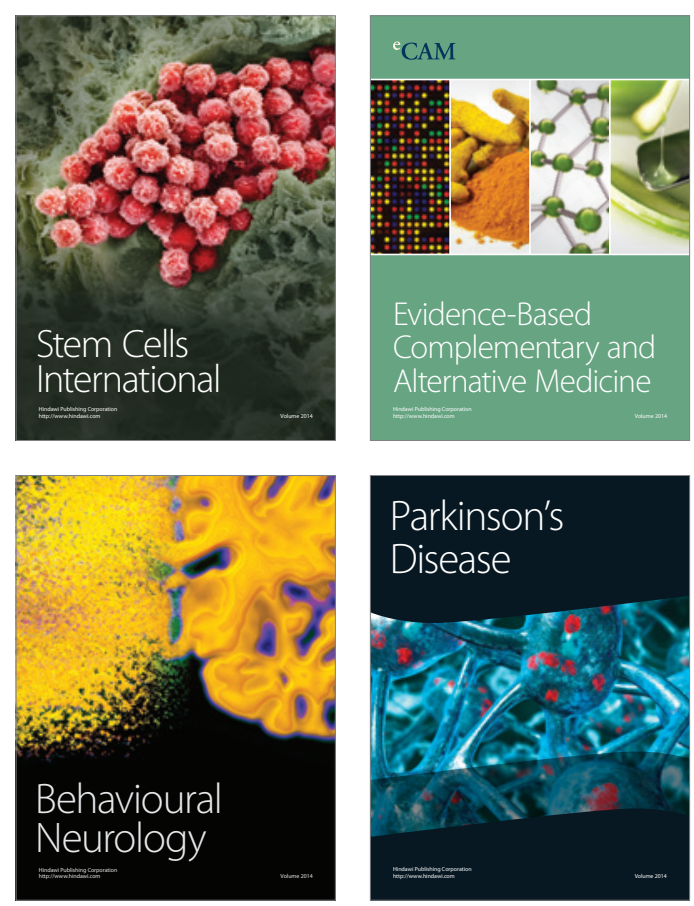

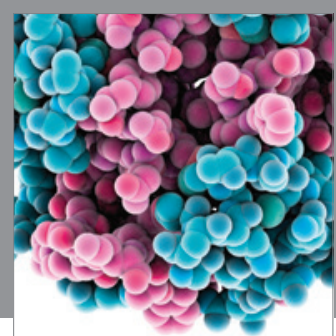

Journal of
Diabetes Research

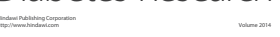

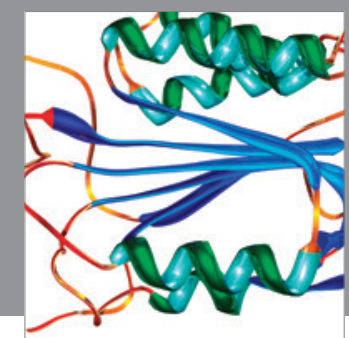

Disease Markers
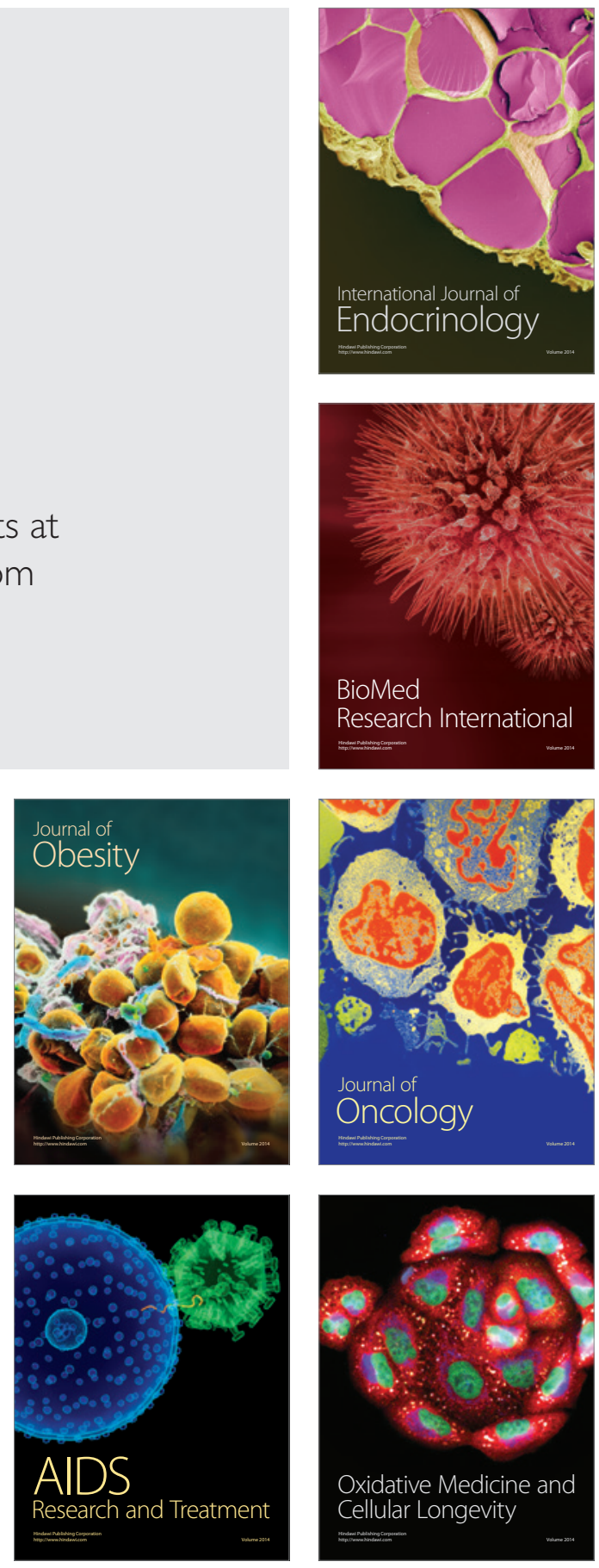